\title{
Mandibular prognathism caused by acromegaly - a surgical orthodontic case
}

\author{
Martin Gosau ${ }^{1}$, Corinna Vogel ${ }^{2}$, Antonios Moralis ${ }^{1}$, Peter Proff 3 , \\ Johannes Kleinheinz ${ }^{* 4}$ and Oliver Driemel ${ }^{1}$
}

\begin{abstract}
Address: ${ }^{1}$ Department of Cranio-Maxillo-Facial Surgery, University of Regensburg, Regensburg, Germany, ${ }^{2}$ Institute of Pathology, University of Regensburg, Regensburg, Germany, ${ }^{3}$ Department of Orthodontics, University of Regensburg, Regensburg, Germany and ${ }^{4}$ Department of CranioMaxillofacial Surgery, University of Münster, Münster, Germany

Email: Martin Gosau - martin.gosau@klinik.uni-regensburg.de; Corinna Vogel - corinna.vogel@klinik.uni-regensburg.de; Antonios Moralis - antonios.moralis@klinik.uni-regensburg.de; Peter Proff - Peter.Proff@klinik.uni-regensburg.de; Johannes Kleinheinz* - Johannes.Kleinheinz@ukmuenster.de; Oliver Driemel - oliver.driemel@klinik.uni-regensburg.de

* Corresponding author
\end{abstract}

Published: 6 August 2009

Head \& Face Medicine 2009, 5:16 doi:10.1 186/1746-160X-5-16
Received: 2 January 2009

Accepted: 6 August 2009

This article is available from: http://www.head-face-med.com/content/5/1/16

(C) 2009 Gosau et al; licensee BioMed Central Ltd.

This is an Open Access article distributed under the terms of the Creative Commons Attribution License (http://creativecommons.org/licenses/by/2.0), which permits unrestricted use, distribution, and reproduction in any medium, provided the original work is properly cited.

\begin{abstract}
A 22-year-old man presented for orthodontic surgery because of mandibular prognathism. Clinical symptoms suggested acromegaly, and diagnosis was verified by an endocrinologist as well as by radiograph. Bilateral mandibular prognathism often represents the first and most striking physical characteristic of acromegaly; usually, it is also the main reason why patients seek help from orthodontists or maxillo-facial surgeons. This case report recapitulates the clinical and histopathological findings in pituitary growth hormone $(\mathrm{GH})$ adenomas and emphasises their importance in surgical orthodontic planning. Mandibular prognatism, macroglossia and abnormal growth of hands and feet represent strong indicators for the diagnosis of acromegaly. This disease and its complications not only affect the entire body but increase mortality if the pituitary gland tumour remains untreated.
\end{abstract}

\section{Introduction}

Pituitary adenomas have a variety of clinical manifestations that are related to excessive hormone secretion by the tumour, hormone deficits by normal pituitary gland tissue and the expansion of tumour mass. Most patients have a 5- to 10-year history of changes in facial features before acromegaly is diagnosed $[1,2]$. Our case report recapitulates the clinical and histopathological findings in pituitary GH adenomas and associated acromegaly and emphasises their importance in surgical orthodontic planning.

\section{Clinical history}

A 22-year-old man was referred to our hospital for orthognathic surgery after 12 months of presurgical orthodontic treatment (fig. 1). Physical examination showed pronounced mandibular prognathism, a widened and thickened nose, prominent supraorbital ridges, thick and coarsened lips and marked facial lines (fig. 2). Intraorally, macroglossia was evident, impairing speech. The patient reported that mandibular prognathism had began to develop 4 years previously. Additionally, his shoe size and hand size had increased considerably during the last few months (fig. 3). 


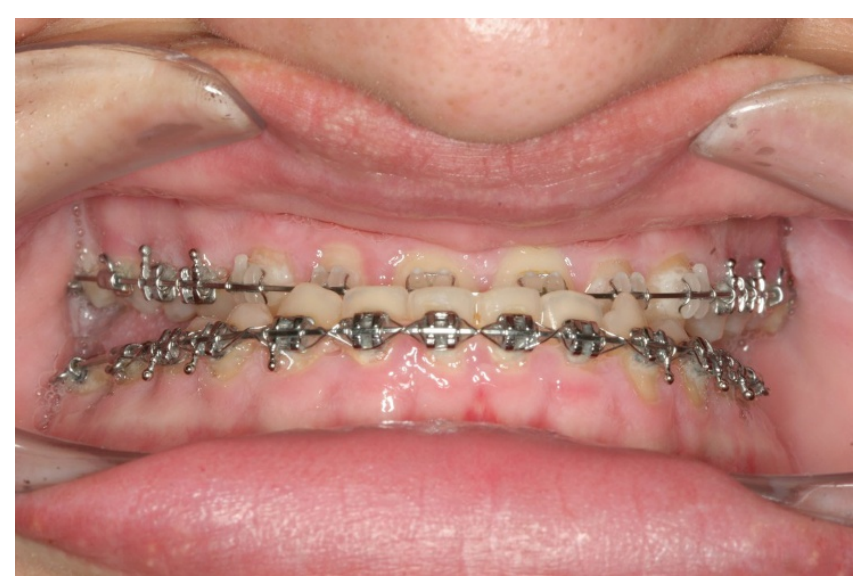

Figure I

Initial intraoral photograph showing Angle class III malocclusion.

Lateral cephalometric radiograph examination showed massive mandibular prognathism, prominent supraorbital ridges and an enlarged sella turcica (fig. 4). Additionally, magnetic resonance imaging (MRI) scans confirmed the expansively growing tumour mass within and above the sella turcica (fig. 5). Furthermore, the entire calvarian bone was thickened, thus confirming the provisional diagnosis of acromegaly. The patient had been referred for examination by an endocrinologist. Diagnosis of a pituitary GH producing macroadenoma was confirmed as well as reactive hyperprolactinaemia and deficiency of the gonadotropin axis. Diabetes mellitus was not found.

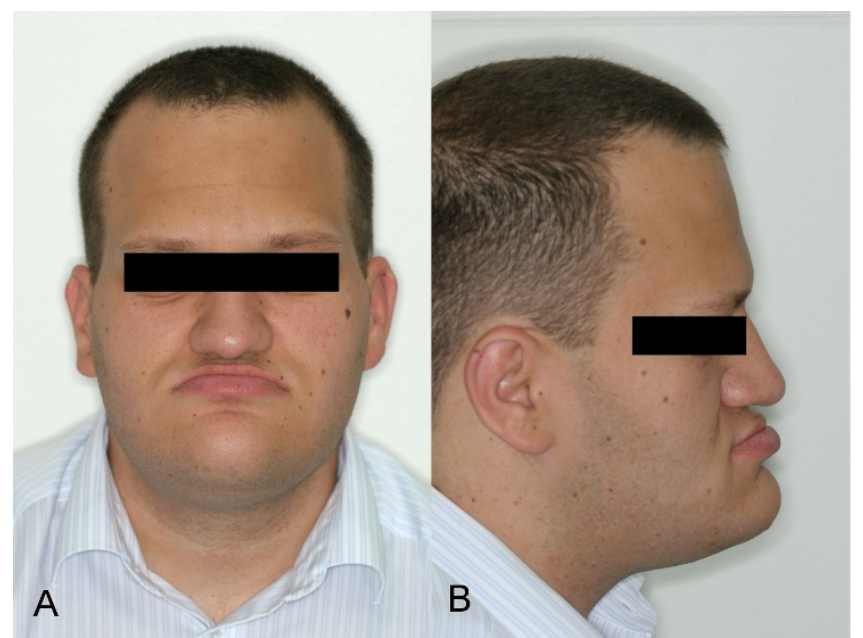

\section{Figure 2}

Initial facial photographs (2a: frontal and 2b: lateral view).

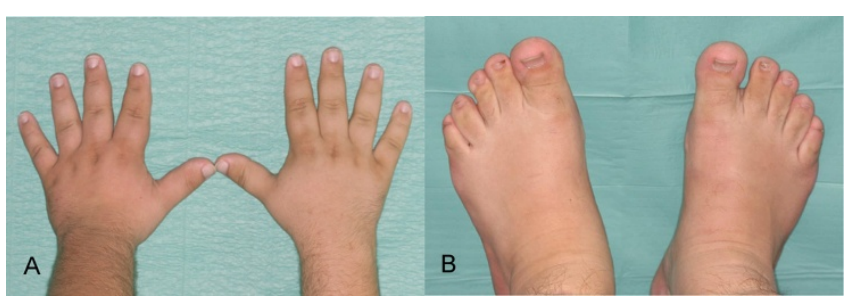

Figure 3

Initial hands and feet photograph.

Endocrinological examination showed increased levels of the insulin-like growth factor-I (IGF-I) $(627.0 \mathrm{ng} / \mathrm{ml}$; norm: 117.0 to $329.2 \mathrm{ng} / \mathrm{ml}$ ), increased prolactin (63.69 $\mu \mathrm{g} / \mathrm{l}$; norm: 2.10 to $17.7 \mu \mathrm{g} / \mathrm{l})$ and depressed testosterone levels $(0.84 \mu \mathrm{g} / \mathrm{l}$; norm: 2.41 to $8.30 \mu \mathrm{g} / \mathrm{l})$. Ultrasonography showed hepatosplenomegaly and an enlarged left kidney. In addition, colonoscopy showed dilatation of the colonic lumen. Ophthalomological screening showed a large bi-temporal visual field defect due to tumour compression of the optic chiasm. The patient underwent transsphenoidal surgery with complete tumour resection.

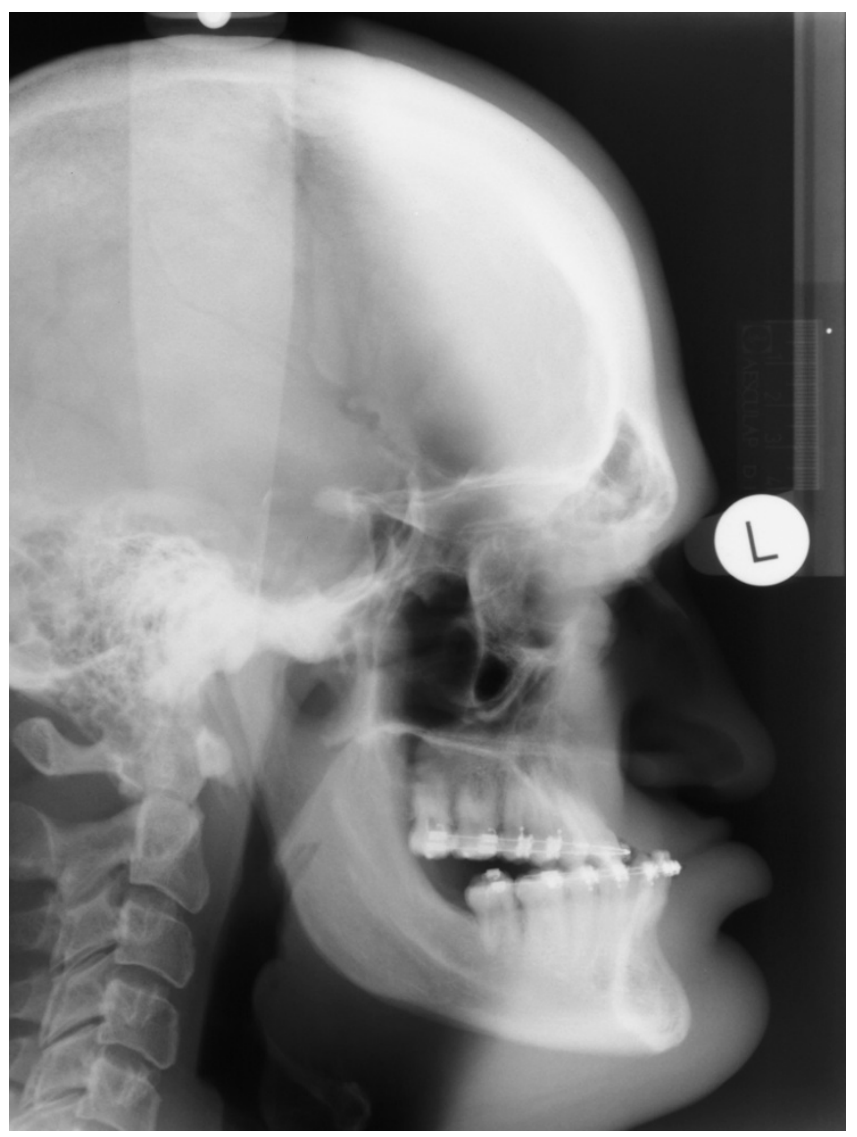

Figure 4

Lateral cephalometric radiograph. 


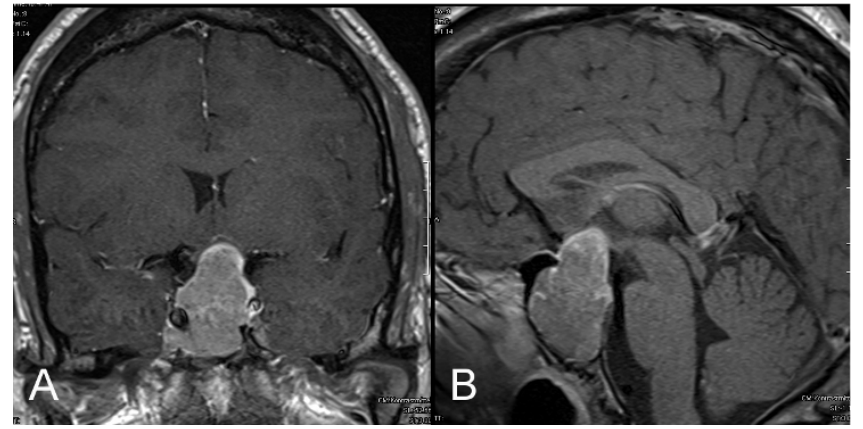

Figure 5

MRIs of tumour site. $5 a$. coronal 5b. sagittal: MRI scans show extensive growth in and above the sella turcica with a total volume of $4.7 \times 2.9 \times 2.2 \mathrm{~cm}^{3}$.

Histological examination showed a highly vascularised pituitary adenoma with a diffuse (solid) growth pattern. Higher magnification showed uniform cells with broad eosinophilic cytoplasm and round to oval nuclei (fig. 6a). The proliferation index was very low with approximately $3 \%$ of cells showing immunoreactivity against MiB-1 (fig. 6b). Parts of the tumour cells showed immunopositivity for prolactin in peripheral parts of cytoplasm (fig. 6c). However, no immunoreactivity was present that provided an antibody against the human growth hormone (fig. 6d).

Reestablishment of endocrine balance would be followed by mandibular osteotomies to reestablish facial harmony and Angle class I occlusion.

\section{Discussion}

Since symmetrical mandibular prognathism can be part of syndromal growth abnormality, this disease is usually noticeable shortly after birth or in early childhood. Nonsyndromal growth abnormalities of the jaws are mainly due to genetic or unknown factors. The third group are acquired growth abnormalities of the jaws. When symmetrical bilateral mandibular prognathism is noticed, the diagnosis of acromegaly should always be taken into consideration [3].

Acromegaly is a rare disease with a prevalence of 40 to 70 cases per million people in the population and an annual incidence of 3 to 4 new patients per million [4,5]. Owing to its insidious onset, acromegaly is often diagnosed late ( 4 to over 10 years after onset) at an average age of about 40 years. The disease affects men and women equally $[6,7]$.

In our patient, the diagnosis of acromegaly was considered because of the patient's manifestations and symptoms at first presentation. Mandibular prognathism is amongst the most commonly found oral manifestations of acromegaly and it was the main reason for the patient to seek orthodontic treatment. Enlargement of the lips and the tongue, such as in our patient, may impair swallowing, chewing and speaking. Frontal bossing, prognathism, macroglossia and an increased size of hands and feet have often been described in the literature as cosmetic changes associated with GH adenomas [2,8-10]. All these changes were present in our patient. Lateral cephalometric radiograph examination of our patient showed massive mandibular prognathism, prominent supraorbital ridges and an enlarged sella turcica. Patients with acromegaly usually exhibit enlargement of all parts of the neurocranium and orofacial bones except the maxilla. The mandible usually shows the biggest enlargement, and the ramus is more affected than the body of the mandible $[11,12]$. The enlargement of the sella turcica caused by the tumour expansion of the pituitary gland is a striking manifestation that is detectable on lateral cephalometric radiographs in almost every patient with acromegaly $[5,11,13]$. Other symptoms reported by our patient included fatigue, daytime somnolence and joint pain.

Decreased energy, osteoarthritis and somnolence occur in about $50 \%$ of patients [2,9]. Patients also exhibit cardiovascular hypertension, congestive heart failure and impaired glucose metabolism, but these diseases were not present in our patient. Diabetes mellitus, sleep apnea (90\%), lumbar stenosis and carpal tunnel syndrome (20\%) are other possible manifestations of GH adenomas $[1,7,14,15]$. In adolescents, GH excess manifests clinically as acromegaly and gigantism if the onset of the disease occurs before the closure of the epiphyseal plates $[8,10,16]$.

Adenomas that grow upwards or expand massively, such as in our patient, may compress the optic chiasm. Such a compression may lead to visual field defects, which begin in the superior temporal sectors and then progress to bitemporal hemianopsia. Persistent compression may lead to blindness. Routine assessment of visual fields and acuity is therefore essential.

Measurement of GH response to glucose load is the standard diagnostic test. An increase in the serum concentration of IGF-I, the main GH dependent growth factor, confirms this diagnosis $[2,10]$. MRI has emerged as the imaging modality of choice for evaluating pituitary glands [8]. Some adenomas are mixed; mixed GH- and prolactin (PRL)-secreting adenomas occur frequently (25\%). Therefore, elevated prolactin levels, such as in our patient, are not unusual.

Available treatment options include surgery, medication and radiotherapy [16]. Trans-sphenoidal surgery is regarded as the first-line treatment of acromegaly [9]. 


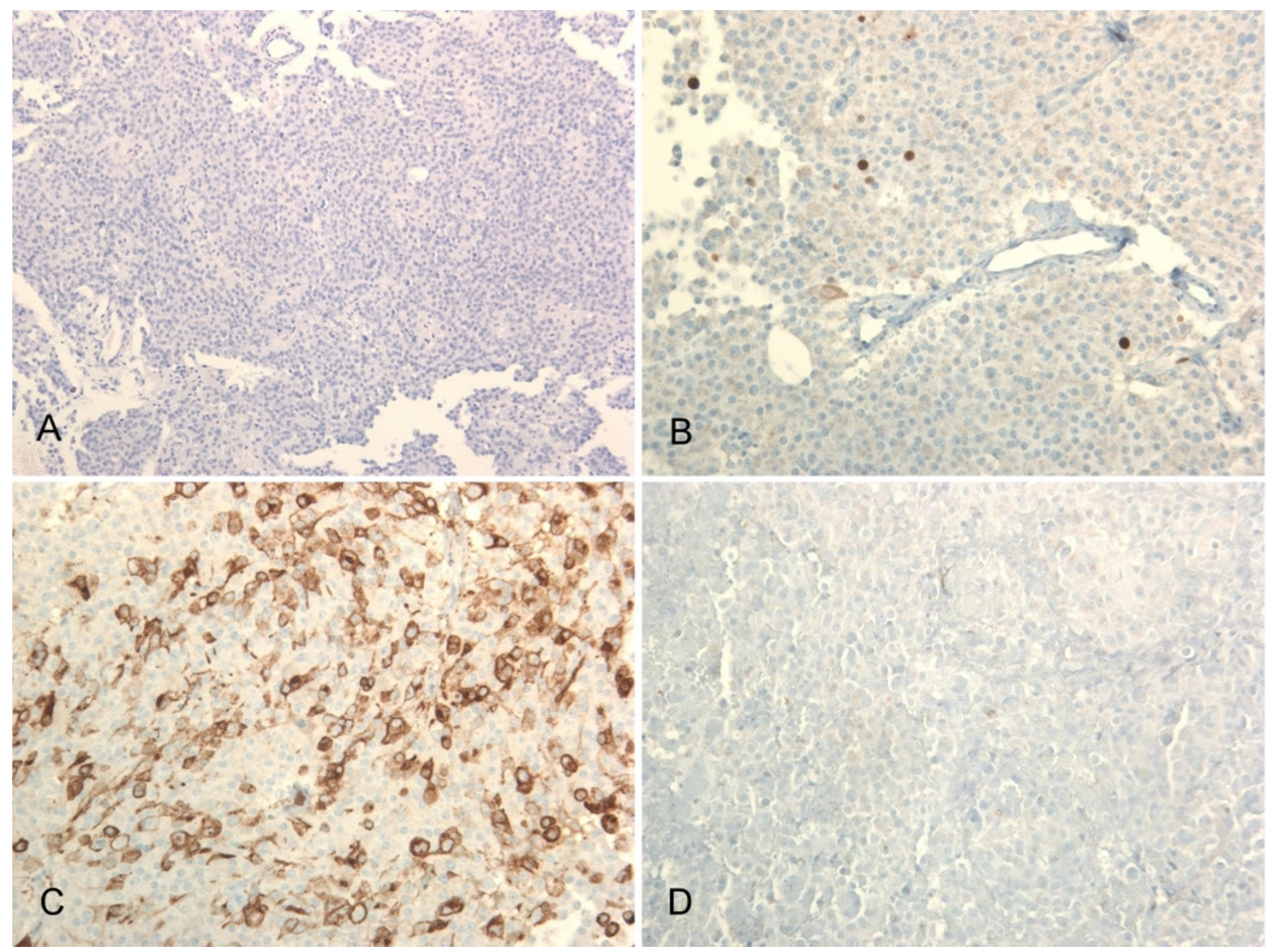

Figure 6

Highly vascularised pituitary adenoma with diffuse (solid) growth pattern. Higher magnification shows uniform cells with broad eosinophilic cytoplasm and round to oval nuclei (Hematoxylin and Eosin, A 100x). The proliferation index is very low with approximately $3 \%$ of cells showing immunoreactivity against MiB-I (B 200x). Some tumour cells show immunopositivity for prolactin in the peripheral areas of the cytoplasm (C 200x). However, no immunoreactivity was present that provided an antibody against the human growth hormone (hGH, D 200x).

Depending on the tumour size, long-term remission is achieved in $50 \%[9]$ to $67 \%[10,17]$ of patients, but safe removal of all tumour tissue can be difficult. Microadenomas (less than $10 \mathrm{~mm}$ in diameter) are more amenable to cure. Preoperative GH concentration seems to be the best indicator for successful treatment and a permanent reduction of GH and IGF-I [18]. If surgery fails to cure acromegaly, medical treatment with somatostatin analogues is recommended rather than radiotherapy [10]. Regardless of the initial choice of treatment, patients should be followed up indefinitely $[2,10,16]$. Our patient was treated with trans-sphenoidal surgery, which adequately reduced GH and IGF-I levels up to six months postoperatively.
After a permanent reduction of GH and IGF-I levels, the enlarged soft tissue regresses gradually [19]. However, only little improvement in bone changes may be expected. After a stable reduction of GH and IGF-I levels of at least two years, bimaxillary osteotomy may be conducted for orthognatic correction and reduction of supraorbital ridges in one single procedure. However, late relapses may occur due to a recurrence of pituitary gland adenoma $[12,20,21]$.

\section{Conclusion}

Acromegaly is a rare disease that is responsible for bilateral mandibular prognathism in adults. Excess of growth hormone and local tumour growth of the pituitary gland affect the entire body and increase mortality. In most 
patients, this disease is diagnosed far too late. Orthodontic and maxillo-facial surgeons dealing with orthognatic surgery should be well aware of this disease as patients usually present with them first because of striking mandibular growth. In case of mandibular prognatism in combination with enlargement of lips, nose, tongue, hands and feet followed by visual field defects, sleep apnea, decreased energy and osteoarthritis, every clinician should consider the diagnosis of acromegaly. Although acromegaly is a rare disease, its symptoms are striking and can hardly be misconstrued.

\section{Competing interests}

The authors declare that they have no competing interests.

\section{Authors' contributions}

GM and MA analysed the patient's history, reviewed all patient data and drafted the manuscript. VC carried out the histological analysis, wrote the histological part of the paper and contributed to the writing of the final version. $\mathrm{DO}, \mathrm{PP}$ and $\mathrm{KJ}$ were involved in revising the article. Each author reviewed the paper for content and contributed to the writing of the manuscript. All authors approved the final report.

\section{Acknowledgements}

Written consent for publication was obtained from the patient.

\section{References}

I. Cook DM, Ezzat S, Katznelson L: AACE Acromegaly Guidelines Task Force. AACE Medical Guidelines for Clinical Practice for the diagnosis and treatment of acromegaly. Endocrine Practice 2004, 10:213-225.

2. Vitral RW, Tanaka OM, Fraga MR, Rosa EA: Acromegaly in an orthodontic patient. Am J Orthod Dentofacial Orthop 2006, 130:388-90.

3. Tornes K, Gilhuus-Moe O: Correction of jaw deformities subsequent to treatment of acromegaly. Int J Oral Maxillofac Surg 1986, 15:446-50.

4. Holdaway IM, Rajasoorya C: Epidemiology of acromegaly. Pituitary 1999, 2:29-4I.

5. Cohen RB, Wilcox CW: A case of acromegaly identified after patient complaint of apertognathia. Oral Surg Oral Med Oral Pathol 1993, 75(5):583-6.

6. Ezzat S, Forster MJ, Berchtold P, Redelmeier DA, Boerlin V, Harris AG: Acromegaly. Clinical and biochemical features in $\mathbf{5 0 0}$ patients. Medicine (Baltimore) 1994, 73:233-40.

7. Melmed S: Acromegaly. In The Pituitary Edited by: Melmed S. Malden, Mas, USA: Blackwell Science Inc; 2002:419-54.

8. Jane JR Jr, Laws ER Jr: Surgical management of pituitary adenomas. Singapore Med J 2002, 6:318-23.

9. Hurley DM, Ho KKY: Pituitary disease in adults. Med J Aust 2004, 180:419-25.

10. Chanson P, Salenave S: Acromegaly. Review. Orphanet J Rare Dis 2008, 3:1-17.

II. Dostálová S, Sonka K, Smahel Z, Weiss V, Marek J: Cephalometric assessment of cranial abnormalities in patients with acromegaly. J Craniomaxillofac Surg 2003, 3 I (2):80-7.

12. Chung KC, Buchman SR, Aly HM, Trotman CA: Use of modern craniofacial techniques for comprehensive reconstruction of the acromegalic face. Ann Plast Surg 1996, 36(4):403-8.

13. Sugata T, Myoken Y, Tanaka S: Acromegaly identified in a patient with a complaint of malocclusion. Oral Surg Oral Med Oral Pathol Oral Radiol Endod 1998, 85(I):44-6.

14. Klibansk A, Zervas NT: Diagnosis and management of hormone secreting pituitary adenomas. $N$ Engl J Med I99I, 324:822-3I.
15. Cuccia AM, Campisi G, Cannavale R, Colella G: Obesity and craniofacial variables in subjects with obstructive sleep apnea syndrome: comparisons of cephalometric values. Head Face Med 2007, 22:4I.

16. Arafah BM, Nasrallah MP: Pituitary tumors: pathophysiology, clinical manifestations and management. Endocr Relat Cancer 200I, 8:287-305.

17. Laws ER, Vance ML, Thapar K: Pituitary surgery for the management of acromegaly. Horm Res 2000, 53:7I-5.

18. Nomikos P, Buchfelder M, Fahlbusch R: The outcome of surgery in 668 patients with acromegaly using current criteria of biochemical "cure". Eur J Endocrinol 2005, I 52:379-87.

19. Sugar A: Surgical correction of residual facial deformity following treatment of acromegaly. J Maxillofac Surg 1986, I4(I): 14-7.

20. Yagi T, Kawakami M, Takada K: Surgical Orthodontic Correction of Acromegaly with Mandibular Prognathism. Angle Orthod 2004, 74:|25-|3|.

21. Jackson IT, Meland NB, Keller EE, Sather AH: Surgical correction of the acromegalic face. A one stage procedure with a team approach. J Craniomaxillofac Surg 1989, I7(1):2-8.
Publish with BioMed Central and every scientist can read your work free of charge

"BioMed Central will be the most significant development for disseminating the results of biomedical research in our lifetime. " Sir Paul Nurse, Cancer Research UK

Your research papers will be:

- available free of charge to the entire biomedical community

- peer reviewed and published immediately upon acceptance

- cited in PubMed and archived on PubMed Central

- yours - you keep the copyright

Submit your manuscript here:

http://www.biomedcentral.com/info/publishing_adv.asp
BioMedcentral 